DOI: https://doi.org/10.29166/tyc.v1i22.3103

\title{
Octubre, once días que aún nos estremecen. Reseña del texto Estallido, la rebelión de octubre en Ecuador
}

\section{Leonidas Iza, And rés Tapia, Andrés Madrid • 2020}

Quito, Ed. Red Kapari • 342 páginas

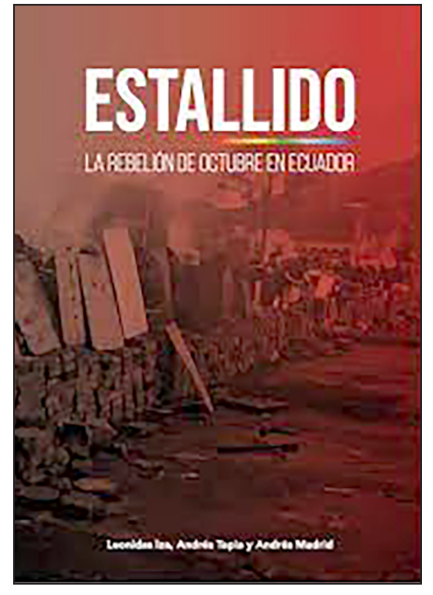

John Reed, en su calidad de periodista, describía los sucesos de los días previos a la revolución rusa como los Diez días que estremecieron al mundo; de la misma manera, Leonidas Iza, Andrés Tapia y Andrés Madrid, reflexionan desde una lectura marxista y desde la praxis como sujetos de lucha, los 11 días de las gloriosas jornadas de movilización vividas en octubre de 2019, como un acontecimiento que estremeció América Latina y lo sigue haciendo.

En este sentido, el texto Estallido es un análisis hecho al fragor de la confrontación de clases y de fuerzas que estrepitaron frente al arremetida del modelo neoliberal y, de fondo, contra los procesos de acumulación y crisis inherentes a la reproducción del sistema capitalista.

A decir de los autores, la rebelión se va cocinando "a fuego lento" producto de la crisis orgánica que en Ecuador se expresaría desde 2014, en gran medida, por la dependencia de nuestra economía al mercado mundial, el creciente endeudamiento externo, la contracción y estancamiento del salario real, el recrudecimiento del extractivismo, el rol del Estado como instrumento para la aplicación de medidas neoliberales, entre otras. Para la ejecución de estas políticas, el Fondo Monetario Internacional ha sido y es determinante, pues el endeudamiento sigue condicionado por ajustes estructurales a la economía ecuatoriana y regional; y finalmente por la aplicación de medidas keynesianas o neoliberales para la administración de la crisis.

Tanto la socialdemocracia en los períodos progresistas, como la hetorodoxia neoliberal -una y otra por diversas vías-, han convergido en el mismo objetivo: imponer el peso de la crisis a los sectores más pobres y dinamizar el patrón de acumulación para la generación de mayor renta en beneficio de los sectores dominantes.

Sin embargo, no solo el embate económico se convirtió en el parteaguas de la rebelión de octubre, sino también la crisis de legitimidad del Estado, expresada en el rechazo a los partidos políticos tradicionales, la desconfianza en los organismos del Estado, y lo bajos niveles de credibilidad de los gobiernos, especial- 
mente el de Lenin Moreno. Estos eventos, explican los autores, coinciden con los ciclos de caída de precios de los productos primarios de exportación, de allí la apuesta del bloque popular para encarar procesos de lucha a nivel nacional.

El despliegue organizativo de la CONAIE es colocado como instancia decisiva en el desenvolvimiento de la rebelión. La CONAIE generó adherencia entre la población y su reivindicación no se quedó en el límite corporativista o etnicista, sino que supo representar el "bienestar de las mayorías". Situación que solo fue posible por la renovación de cuadros dirigenciales emergidos al calor de la lucha contra el neoliberalismo y neodesarrollismo de los últimos años, mismos que han hecho posible el crecimiento de una postura anticapitalista en el seno de la CONAIE.

Se resalta también la movilización espontanea en Quito, misma que habría logrado impulso al ser respaldada por la llegada de las organizaciones indígenas. Se señala, en este sentido, la importancia de las acciones de lucha y solidaridad desplegadas en y desde los barrios y zonas urbano-marginales, así como los vínculos logrados con los sectores de ingresos medios. Además, se rescata la nutrida participación de las mujeres, tanto en el cuidado como al frente de la movilización; y de la juventud, primera fila de la lucha callejera e interpeladora de la trama autoritaria del "poder-realmente-existente".

El decreto 883 fue la punta del iceberg que permitió acelerar las luchas que venían desarrollándose por todo el país desde 2019, y la negociación de la eliminación del decreto fue un claro mensaje de repudio a la política neoliberal y fondomonetarista. Esta se realizó con barricadas encendidas y de manera pública, venciendo el cerco mediático y el discurso hegemónico del terrorismo, vandalismo, y de "las pérdidas" que implicaba para el país la paralización de actividades.

El renovado movimiento indígena que condujo colectivamente la lucha de octubre, junto al proletariado y el subproletariado quiteño, desplazó a la línea reformista visible e institucional que se ha enquistado en Pachakutik; tal es así, que Yaku Pérez, Salvador Quishpe y Lourdes Tibán, entre otros, fueron personajes anodinos que no tuvieron una participación sustancial, debido a que en marcadas ocasiones, Pachakutik, brazo electoral de la CONAIE, se ha distanciado política e ideológicamente de la estructura orgánica del movimiento. Aquello es ahora más evidente tras las últimas elecciones presidenciales, al intentar capitalizar la lucha de octubre únicamente para obtener réditos electorales. La declaración del propio Pérez delata su visión reformista al plantear "la tercera vía" frente a la tendencia de clase que enarbolan los hijos e hijas del primer levantamiento.

Ineludiblemente, octubre está plasmado en la retina de la sociedad ecuatoriana y latinoamericana, ha sido y es experiencia concreta y potencia simbólica, y permitirá renovar las fuerzas para la reorganización de las tareas que el influjo de la lucha, finalmente, impone. Ahora que el continente enfrenta de manera polarizada y firme al sistema civilizatorio que merma la vida de las mayorías explotadas, es prioritario la construcción del proyecto emancipatorio a través de la unidad de la izquierda internacionalista, anticapitalista y antiimperialista, fortalecer y acrecentar el tejido social en el campo popular, sin derivas, ni placebos reformistas inyectados por la socialdemocracia disfrazada de ecologismo o feminismo.

El "poder-realmente-existente" solo se lo confrontará con una tendencia de clase, anticapitalista, sin alianzas y pactos con la derecha o la izquierda institucional que, en gran medida, son exactamente lo mismo.

Jacqueline Artieda

Correo: jdartieda@uce.edu.ec 